\title{
PRINCIPALES RIESGOS Y LÍMITES \\ DE LA APLICACIÓN DEL PRINCIPIO DE IURA NOVIT CURIA \\ EN EL ARBITRAJE NACIONAL
}

\author{
MARCIAL G. GUTIÉRREZ LÚCAR* \\ Universidad de Lima, Lima, Perú \\ mgutierr@ulima.edu.pe
}

Recibido: 28/1/2021 Aprobado: 4/2/2021

doi: https://doi.org/10.26439/iusetpraxis2021.n052.5078

\begin{abstract}
RESUMEN. El principio de iura novit curia es un principio general del derecho, por el cual los jueces se encuentran obligados a aplicar, en los procesos judiciales, las normas respectivas si no han sido invocadas por las partes procesales. Sin embargo, ¿dicha obligación debe ser trasladada a los tribunales arbitrales? La presente investigación intenta acercarnos a una respuesta, así como a los problemas prácticos que se generan cuando los árbitros deciden implementar este principio al emitir su laudo.
\end{abstract}

PALABRAS CLAVE: principio de iura novit curia / tribunal arbitral / debido proceso / motivación / derecho de defensa / derecho de contradicción

\section{MAIN RISKS AND LIMITS OF APPLYING THE PRINCIPLE OF IURA NOVIT CURIA IN NATIONAL ARBITRATION}

ABSTRACT. lura novit curia is a general principle of law by which judges are obliged to apply, in judicial proceedings, the respective law if it has not been invoked by the procedural parties. However, should this obligation be transferred to the arbitral tribunals? This research tries to approach an answer, as well as the practical problems that are generated when arbitrators decide to implement this principle while they issue their award.

KEYWORDS: principle of iura novit curia / arbitral tribunal / due process / motivation / right of self-defense / right to reply

\footnotetext{
* Abogado con mención magna cum laude y con estudios de maestría en Derecho por la Universidad de Lima. Docente adjunto de cursos como Obligaciones y Derecho Procesal Civil en la misma casa de estudios, así como docente invitado en el curso de Arbitrajes Especiales. Actualmente, se desempeña como asociado sénior de la firma Rafael Prado I Litigio Judicial y Arbitral.
} 


\section{INTRODUCCIÓN}

El aforismo iura novit curia, cuya traducción literal es "el tribunal conoce el derecho", como es de común conocimiento, implica que quien vaya a resolver una controversia -originalmente judicial- lo haga aplicando la normativa jurídica adecuada, cuando esta no ha sido invocada por la parte demandante y/o demandada. Ello, claro está, bajo diversos límites como, por ejemplo, la no contravención del derecho al debido proceso de las partes.

Actualmente, no existen mayores dudas conceptuales respecto de los alcances de este aforismo, que ha sido regulado textualmente por el artículo VII del Título Preliminar del Código Civil peruano (en adelante, Código Civil). Sin embargo, consideramos pertinente analizar si corresponde su aplicación en el arbitraje nacional, cuyo tribunal arbitral está constituido por árbitros peruanos y, además, se haya pactado que el Código Civil sea la norma para la solución de la controversia. Adicionalmente, también abordaremos las consecuencias que el proceder del tribunal arbitral puede generar respecto del derecho al debido proceso de las partes arbitrales, de la exigibilidad del laudo y los riesgos para que se inicie un proceso de anulación de laudo.

\section{NORMATIVA APLICABLE A LOS ARBITRAJES Y EL DEBER (O FACULTAD) DE EMPLEAR EL PRINCIPIO DE IURA NOVIT CURIA}

Desde una perspectiva práctica, la normativa y los principios generales que regularán al arbitraje nacional dependerán, principalmente, de los siguientes factores:

1. Primero, de las normas sustantivas empleadas para la resolución de la controversia, conforme a lo pactado por las partes.

2. En segundo lugar, con relación a la lex arbitri y las reglas procedimentales que se establezcan para la tramitación del arbitraje.

3. Por último, por las disposiciones jurídicas aplicables para analizar la existencia, validez o ejecución de la cláusula arbitral, las cuales pueden ser distintas de los empleados para la resolución de la controversia.

En el caso del arbitraje nacional, lo habitual es que se pacte la aplicación del Código Civil para la resolución de la controversia, recordando que el principio de iura novit curia se encuentra positivizado en el artículo VII de su Título Preliminar, el cual establece para los jueces la obligación de aplicar el derecho respectivo al caso concreto. En ese sentido, la primera duda que nos formulamos es si este principio debe ser aplicado de todas maneras en el arbitraje nacional y si corresponde hacerlo con la misma exigencia que a un órgano jurisdiccional. 
Al respecto, debido a la misma naturaleza del principio de iura novit curia, podemos encontrar dos situaciones:

1. La primera de ellas está vinculada a que, al ser un principio general del derecho y positivizado en el artículo VII del Título Preliminar del Código Civil, estaríamos ante un deber exigible no solo a los jueces, sino también a los integrantes de un tribunal arbitral. En este sentido, a fin de evitar cualquier supuesto de responsabilidad, los árbitros tendrían que aplicar este principio.

2. En contraste, debemos tomar en cuenta el contexto en el que se reguló el Código Civil, así como que entró en vigencia en 1984, cuando en nuestro país no existía una actividad arbitral relevante. Asimismo, el artículo VII del Título Preliminar del Código Civil fue pensado para definir un deber de los jueces, lo que está relacionado con que nuestro sistema de justicia estatal cumpla con una finalidad social. Este aspecto no se replica en el arbitraje, en donde se promueve la resolución de una controversia privada y cuyos efectos se mantienen en la confidencialidad de las partes. Adicionalmente, en comparación con un proceso judicial, se presume que en el arbitraje existe igualdad entre las partes arbitrales, quienes han renunciado a la jurisdicción natural y a las garantías que dicho sistema otorga.

Tomando en cuenta lo expuesto, podemos entender que en el arbitraje existe un sistema de autorresponsabilidad asumido por las partes arbitrales, por lo que la omisión en su defensa - como no invocar la norma respectiva- no debería ser suplida por el tribunal arbitral, pues ello implicaría una colisión con su deber de imparcialidad. Sin embargo, no podemos concluir que el principio de iura novit curia no sea aplicado, ya que legalmente existe un límite para el proceder de las partes y el tribunal arbitral: las normas de orden público.

Así, concluimos que el principio de iura novit curia en el arbitraje puede ser entendido como una facultad antes que como un deber del tribunal arbitral. Sin embargo, dicha facultad sí se tornaría un mandato de acción cuando la norma que se debería aplicar es una de orden público. Esto ocurre con los arbitrajes de contrataciones con el Estado o en los de seguros, donde existe una regulación especial y contra la que no puede existir un pacto en contrario.

La exposición realizada hasta el momento tiene por objetivo que quienes accedan al presente trabajo conozcan que el principio de iura novit curia puede ser interpretado en, al menos, dos sentidos, en relación con su aplicación al arbitraje nacional, los que no son contradictorios entre sí. Lo importante es que el lector tenga estas interpretaciones a su disposición, pudiendo suscribir alguna de ellas o generarse una postura distinta, lo que enriquece el debate. 


\section{ALCANCES DEL PRINCIPIO DE IURA NOVIT CURIA}

Independientemente de la postura que se adopte sobre la exigibilidad de la aplicación del principio de iura novit curia al arbitraje, en la presente sección abordaremos sus alcances. Recordemos que este aforismo ha sido regulado en el artículo VII del Título Preliminar del Código Civil de la siguiente manera: "Los jueces tienen la obligación de aplicar la norma jurídica pertinente, aunque no haya sido invocada en la demanda" (Decreto Legislativo N. ${ }^{\circ} 295,1984$ ).

Si bien esta norma está redactada empleando el término los jueces, este podría ser adecuado al de tribunal arbitral, considerando que se haya acordado la aplicación de dicho cuerpo normativo para la resolución de la controversia arbitral, tal como ocurre con el resto ${ }^{1}$ de articulado del Código Civil.

Por otro lado, respecto a los alcances del principio bajo comentario, consideramos pertinente tomar en cuenta los siguientes puntos:

1. El texto expreso del artículo VII del Título Preliminar del Código Civil establece que "los jueces tienen la obligación de aplicar la norma jurídica pertinente". Esto nos conduce a concluir que, sin excepción alguna, quien resuelva una controversia empleando la normativa del Código Civil tiene el poder-deber de impartir justicia, al amparo del supuesto de hecho jurídico respectivo, pese a que no haya sido invocado por las partes, sea mediante la demanda o la contestación de demanda.

2. Prosiguiendo con la lectura expresa del artículo en cuestión, advertimos que hace referencia al deber de aplicación de la norma jurídica pertinente cuando "no haya sido invocada en la demanda". Ello nos permite concluir que no procede este deber cuando el error se debe a la falta de diligencia del demandado. Al respecto, ya que este principio tiene por finalidad la aplicación adecuada de la norma al caso concreto, independientemente de quién sea responsable de la omisión, consideramos que procederá inclusive si el demandado incurre en la falta de precisión.

Cabe mencionar, aunque puede resultar lógico, que el término demanda también comprende a la reconvención interpuesta por la parte demandada en un proceso judicial o en un arbitraje.

3. Si bien el principio de iura novit curia está contenido en una norma sustantiva, no cabe duda de que comprende una disposición procedimental, pues determina

1 A título de ejemplo, contamos con los artículos 1332, 1346, 1440, 1528, 1576 del Código Civil, así como otros, por los que se realiza una expresa referencia al término juez, pero que, sin inconveniente alguno, son adecuados y se modifica dicho término por el de tribunal arbitral, una vez que se pretende aplicar en un arbitraje. 
cómo deberá proceder un juez en un proceso judicial o un tribunal arbitral en un arbitraje.

Con relación a ello, desde una perspectiva puramente judicial, la doctrina española precisa que el pronunciamiento emitido, aplicando este principio, no debe ir en contra de lo requerido (pretensión) ni del sustento de lo peticionado (causa de pedir) (Díez-Picazo y Gullón Ballesteros, 1982, p. 227). Consideramos que con un criterio analógico dichas apreciaciones son trasladables al arbitraje sin problema alguno.

4. Como acertadamente señala la doctrina, exigir a los jueces -así como se pretendería hacerlo con los integrantes de un tribunal arbitral- la aplicación del derecho respectivo al caso concreto se sustenta en la presunción lógica de que ellos conocen lo suficiente de la normativa en cuestión (Espinoza Espinoza, 2011, p. 466). Así pues, se encuentran facultados para identificar las fallas en la invocación realizada por las partes - sea al demandar, contestar la demanda o reconvenir-y, aún más importante, para aplicar el derecho que consideren correcto a la materia de análisis. Esto, sin lugar a dudas, también comprende a las disposiciones de orden público.

5. Al aplicar el principio de iura novit curia, sea el juez o el tribunal arbitral, consideramos necesario que, al emitir un pronunciamiento, se realice una explicación clara del porqué las alegaciones jurídicas realizadas por las partes son impertinentes. Pues, de no hacerlo, se configuraría un claro supuesto de indebida motivación, sea de la sentencia o del laudo, lo que acarrea su nulidad.

6. Por último, un aspecto importante que no se desprende del artículo VII del Título Preliminar del Código Civil es, si se decide hacerlo, ¿cuándo debe comunicarse la posible aplicación del principio de iura novit curia? Este es el principal problema que se identifica no solo en el ámbito judicial, sino también en el arbitral. Asimismo, esta es una de las principales limitantes para que los tribunales arbitrales lo apliquen en su práctica, lo que analizaremos en la presente investigación.

Tomando en cuenta la regulación del aforismo iura novit curia en nuestro ordenamiento, nos referiremos a las obligaciones generales del tribunal arbitral y, posteriormente, a las situaciones que se generan por la interrelación de ambas instituciones.

\section{LA CLÁUSULA ARBITRAL Y LAS OBLIGACIONES DEL TRIBUNAL ARBITRAL}

No cabe duda de que quienes celebran un acuerdo arbitral lo hacen con la finalidad de encomendar la resolución de una controversia al tribunal arbitral, dado que las principales virtudes del arbitraje, como lo ha reconocido la doctrina internacional (González 
de Cossío, 2011, p. 124), son (i) la especialidad de quienes integran el tribunal arbitral y, además, (ii) la eficiencia del arbitraje en sí mismo, pues un experto neutral le dedicará el tiempo necesario para que la controversia sea resuelta adecuada y oportunamente.

En ese sentido, como consecuencia del encargo realizado por las partes suscriptoras del acuerdo de arbitraje, el tribunal arbitral estará sujeto a diversas obligaciones - aceptadas por la doctrina y reguladas normativamente-, así como contará con determinadas facultades de actuación:

\section{Conducción del arbitraje}

El tribunal arbitral cuenta con las facultades para administrar el arbitraje bajo los parámetros que estime pertinente, al ser considerado como el director del mismo. Ello no solo se desprende de la posición mayoritaria de la doctrina, sino que, además, ha sido regulado por el numeral 3$)^{2}$ del artículo 3 del Decreto Legislativo N. ${ }^{\circ} 1071$, Decreto Legislativo que norma el arbitraje (en adelante, Ley de Arbitraje).

Esta facultad de dirección del arbitraje es relevante, dado que permitirá al tribunal arbitral que adopte, en principio, la mejor decisión respecto a cómo proceder si identifica que debe hacer uso del iura novit curia, evitando la afectación de alguno de sus demás deberes como director del arbitraje.

\section{Debido proceso}

El derecho al debido proceso comprende el "dar a las partes oportunidad de hacer valer sus derechos. El fundamento y razón de ser de dicho principio es incuestionable" (González de Cossío, 2011, p. 444). Esta obligación se encuentra regulada en el numeral 2) del artículo 34 de la Ley de Arbitraje, que dispone: “El tribunal arbitral deberá tratar a las partes con igualdad y darle a cada una de ellas suficiente oportunidad de hacer valer sus derechos" (Decreto Legislativo N. ${ }^{\circ} 1071,2008$ ).

En cuanto a lo mencionado en el párrafo anterior, podemos señalar que algunas de las manifestaciones del derecho al debido proceso son el ejercicio del derecho de defensa, el derecho a la prueba y el de contradicción.

En lo que respecta al arbitraje nacional peruano, no cabe duda de que los principios antes mencionados se encuentran regulados en la Ley de Arbitraje, específicamente en

2 Artículo 3 de la Ley de Arbitraje: “[... 3. El tribunal arbitral tiene plenas atribuciones para iniciar y continuar con el trámite de las actuaciones arbitrales, decidir acerca de su propia competencia y dictar el laudo. [...]". 
(i) el numeral $1^{3}$ de su artículo 39 (derecho de defensa y de contradicción) y (ii) el numeral $2^{4}$ de su artículo 39 (derecho a la prueba).

Asimismo, no debemos perder de vista que el derecho de defensa comprende la facultad que tienen las partes arbitrales para defenderse en el arbitraje, mientras que el de contradicción implica garantizar que cualquiera de las partes arbitrales conozca las actuaciones de la contraria y, de esa manera, ejerza su derecho de defensa. Por otro lado, el derecho a la prueba supone que, en el marco del ejercicio del derecho de defensa y el de contradicción, cualquiera de las partes arbitrales cuente con la oportunidad de respaldar sus aseveraciones con los medios de prueba respectivos, en las oportunidades preestablecidas.

Como parte de la tramitación del arbitraje, es probable que el tribunal arbitral se encuentre ante situaciones que generen la contravención al debido proceso, como podría ocurrir cuando se presenta el dilema de cómo aplicar el principio de iura novit curia. En ese caso, la doctrina nos propone una salida:

Si bien el tema es debatible y dependiente de las circunstancias del caso, existen dos sugerencias generales que pueden hacerse. La primera a los árbitros: en caso de duda, vale la pena ser conservador sobre las medidas/decisiones que pueda parecer que le restan a una parte su derecho a presentar plenamente su caso. A su vez, deben documentarse con detalle en el laudo los motivos por los que el tribunal optó por cierta medida que pudiera, a primera impresión de quien no presenció los hechos, parecer que incumple el principio [cursivas añadidas]. La segunda a los jueces que conozcan de la posible nulidad o no-reconocimiento/ejecución del laudo: cuando una medida adoptada por un tribunal arbitral parezca no haberle permitido a una parte ejercer sus derechos, esta debe aquilatarse contra el hecho de que el tribunal es quien tiene mayor conocimiento sobre el caso y que tiene la misión de seguir el procedimiento con celeridad y orden, por lo que es recomendable que solo en casos extremos claramente injustos se le reste validez a un laudo con fundamento en esta circunstancia. (González de Cossío, 2011, p. 444)

Según la cita anterior, el tribunal arbitral debe ser extremadamente cauteloso cuando adopte una decisión que implique, de cierta manera, una contravención al debido proceso. Es necesario que dicha recomendación sea tomada en cuenta por el tribunal arbitral cuando advierta que existe la posibilidad de aplicar el principio de iura novit curia, así como cuando vaya a emitir su laudo.

3 Artículo 39 de la Ley de Arbitraje, numeral 1: "Dentro del plazo convenido por las partes o determinado por el tribunal arbitral y a menos que las partes hayan acordado algo distinto respecto del contenido de la demanda y de la contestación, el demandante deberá alegar los hechos en que se funda, la naturaleza y las circunstancias de la controversia y las pretensiones que formula y el demandado deberá establecer su posición respecto a lo planteado en la demanda. [...]".

4 Artículo 39 de la Ley de Arbitraje, numeral 2: “Las partes, al plantear su demanda y contestación, deberán aportar todos los documentos que consideren pertinentes o hacer referencia a los documentos $u$ otras pruebas que vayan a presentar o proponer. [...]". 


\section{Igualdad}

El contenido de este principio es totalmente predecible, dado que se resume en que es obligación del tribunal arbitral tratar a las partes de manera igualitaria. Ello implica, sin duda alguna, que a lo largo del procedimiento arbitral las partes se enfrenten entre sí evitando cualquier tipo de situación por la cual se considere que una de estas se encuentre beneficiada respecto de la otra.

El numeral 2 del artículo 34 de la Ley de Arbitraje establece de forma expresa que "el tribunal arbitral deberá tratar a las partes con igualdad" (Decreto Legislativo N. ${ }^{\circ} 1071$, 2008). Así pues, no nos encontramos ante una mera premisa que proviene de la doctrina, sino que cuenta con un respaldo normativo.

\section{Motivar el laudo}

Como hemos comentado previamente, la finalidad del arbitraje es poner fin a una controversia, lo que será posible mediante la emisión del laudo. Este deberá cumplir con requisitos mínimos como ser debidamente motivado, dado que es la única manera en que ambas partes conozcan, a ciencia cierta, por qué el tribunal arbitral ha decidido darle la razón a una de ellas y, consecuentemente, a rechazar la posición de la otra (González de Cossío, 2011, p. 448).

Sobre este punto, también nos encontramos ante una obligación de naturaleza legal, que está regulada en el numeral $1^{5}$ del artículo 56 de la Ley de Arbitraje.

\section{Emitir un laudo ejecutable}

Por último, las partes que suscriben un acuerdo arbitral buscan que el arbitraje culmine con la emisión de un laudo y que este surta efectos de forma integral, siendo esta la única manera de poner fin a la controversia que ha sido sometida al procedimiento arbitral. Ello implica, sin lugar a dudas, que el laudo deba ser calificado como ejecutable y, en tal sentido, se cumpla con la finalidad del procedimiento arbitral.

Los deberes y facultades del tribunal arbitral que hemos desarrollado en la presente sección deben ser tomados en cuenta por los árbitros al definir no solo si deben aplicar el principio de iura novit curia, sino, además, cómo corresponde proceder para evitar privar del debido proceso a alguna de las partes del arbitraje.

$5 \quad$ Artículo 56 de la Ley de Arbitraje, numeral 1: "Todo laudo deberá ser motivado, a menos que las partes hayan convenido algo distinto o que se trate de un laudo pronunciado en los términos convenidos por las partes conforme al artículo 50. Constarán en el laudo la fecha en que ha sido dictado y el lugar del arbitraje determinado de conformidad con el numeral 1 del artículo 35 . El laudo se considera dictado en ese lugar. [...]". 


\section{DILEMAS PRÁCTICOS VINCULADOS A LA APLICACIÓN DEL IURA NOVIT CURIA}

La implementación del principio de iura novit curia, en caso así lo decida el tribunal arbitral, aparentemente, comprende la sola aplicación de una norma jurídica al caso concreto, por lo que no se deberían generar mayores problemas. Sin embargo, consideramos que ello no es del todo cierto, porque existen supuestos en los cuales, debido a la oportunidad en la que el tribunal arbitral decide implementar esta medida, se afecta al debido proceso de las partes arbitrales.

El punto de partida de este análisis guarda vinculación con cuándo el tribunal arbitral advierte que, siquiera, ha considerado la aplicación del principio de iura novit curia al momento de laudar, pues detectó que existe un inconveniente con la normativa invocada por las partes y, consecuentemente, decide suplir dicha omisión.

Conforme a la práctica arbitral nacional, hemos identificado diversos escenarios que se generan por la aplicación del principio de iura novit curia, así como algunas medidas que se pueden implementar por el tribunal arbitral con la finalidad de evitar que su proceder sea cuestionado mediante un proceso judicial de anulación de laudo. Veamos:

1. El primer escenario que consideramos no debe ocurrir por motivo alguno: es el que denominamos como laudo sorpresa, situación que se configura cuando las partes del arbitraje toman conocimiento, al ser notificadas con el laudo, de que el tribunal arbitral aplicó el principio de iura novit curia, pese a que ni el demandante ni el demandado tuvieron la oportunidad de pronunciarse sobre la normativa invocada al emitir el pronunciamiento.

Nuestro rechazo a la situación descrita se sustenta en que, si bien el tribunal arbitral se encuentra obligado a aplicar el derecho al caso concreto, ello no lo autoriza a hacerlo en lo que sería una clara contravención al debido proceso, ya que se debe garantizar a las partes del arbitraje el ejercicio a su derecho de defensa y, de ser necesario, a proporcionar los medios probatorios que sustenten o rebatan el supuesto de hecho en cuestión.

Veamos un ejemplo de lo grave que puede ser un laudo sorpresa. Nuestro ordenamiento establece que la caducidad puede ser aplicada de oficio (artículo 2006 del Código Civil), lo que en el arbitraje se materializa cuando el tribunal arbitral emite su laudo. Sin embargo, también existe la posibilidad de que el plazo de caducidad haya estado suspendido (artículo 2005 del Código Civil), por lo que, garantizando el derecho al debido proceso y evitando la emisión de un pronunciamiento injusto, se debe otorgar a las partes la oportunidad de ejercer su derecho de defensa, exponiendo lo que consideren pertinente e incorporando las pruebas que respalden sus aseveraciones. En caso de que el tribunal arbitral no comunique a las partes arbitrales que analizará la declaración de oficio de la 
caducidad del derecho, puede configurarse un supuesto gravoso y lesivo para la parte perdedora, no solo por su afectación al debido proceso, sino porque el pronunciamiento es injusto.

La situación descrita es la menos deseada y no permitida por un tribunal arbitral, porque emitiría un laudo totalmente viciado y que podría ser cuestionado sin mayor inconveniente. El remedio jurídico que las partes arbitrales pueden emplear para cuestionar este laudo es la anulación por la vía judicial, alegando que no pudieron hacer valer sus derechos, de acuerdo con el inciso b), numeral 2 del artículo 63 de la Ley de Arbitraje.

2. En segundo lugar, consideramos la posibilidad de que el tribunal arbitral advierta que puede aplicar el principio de iura novit curia una vez que se encuentre dentro del plazo para emitir el laudo. En ese escenario, del intercambio de opiniones que hemos sostenido con diversos árbitros, las principales alternativas que suelen adoptarse, con la finalidad de garantizar el debido proceso, son estas:

a. Suspender el plazo destinado para la emisión de laudo y solicitar a las partes que se pronuncien sobre la normativa que posiblemente se aplique al caso concreto, así como habilitar la alternativa de que presenten los medios probatorios que respalden sus posturas.

b. Dejar sin efecto la orden procesal (usualmente denominada así en nuestro país) por la que se otorgó el plazo para laudar y retornar a la etapa probatoria, planteando a las partes un debate específico sobre la norma que el tribunal arbitral analiza aplicar mediante el principio de iura novit curia, así como asegurando su derecho a probar las afirmaciones que estimen.

Habiendo garantizado el derecho al debido proceso de ambas partes, el tribunal arbitral reiniciaría o establecería un nuevo plazo para laudar, según la alternativa que haya adoptado. Entonces, se encontraría facultado para, a su discreción, emitir un laudo sustentado en la normativa no alegada por las partes arbitrales, sin que pueda cuestionarse una supuesta contravención al debido proceso.

3. El tercer y más sencillo de los escenarios es aquel en el que el tribunal arbitral advierte, al concluir la etapa postulatoria -entiéndase por ello a la recepción de la contestación a la demanda o de la contestación a la reconvención-, que las partes arbitrales cometieron un error en la norma invocada para el respaldo de sus posiciones. Así, durante la etapa probatoria, el tribunal arbitral estará habilitado para incluir en el debate la procedencia de la norma que analiza aplicar, garantizando el derecho al debido proceso de las partes arbitrales. Ello implicará la emisión de un laudo que no sería cuestionable por contravenir el debido proceso de las partes. 
4. Finalmente, si bien este es un hecho no vinculado a la oportunidad en la cual el tribunal arbitral decide aplicar el principio de iura novit curia, consideramos que al emitir el laudo es necesario explicar por qué las alegaciones jurídicas de las partes arbitrales no son aplicables, garantizado que las partes conozcan las motivaciones detrás de la decisión del tribunal arbitral.

Deseamos poner fin a la presente sección indicando que los aspectos prácticos identificados son algunos de los que se pueden presentar en la realidad. Por eso, buscamos promover la identificación de nuevos supuestos y salidas que el ámbito arbitral puede brindarnos ante una situación que, sin lugar a dudas, no cuenta con una respuesta definitiva.

\section{CONCLUSIONES}

Primero, debemos indicar que no existe una postura única e irrefutable respecto a la aplicación del principio de iura novit curia en el arbitraje nacional, debido a los argumentos expuestos precedentemente. Pese a ello, entendemos que el debate debe partir de los dos supuestos que hemos identificado: como una aplicación obligatoria de este aforismo o entenderlo como una facultad, que se transformaría en un deber si la norma por aplicar es de orden público.

El segundo aspecto que hay que tomar en cuenta, principalmente por el tribunal arbitral, a fin de proteger al laudo de un futuro cuestionamiento, es que, si evalúan o deciden aplicar el principio de iura novit curia, deberán hacerlo garantizando el derecho al debido proceso de las partes arbitrales, liberando al pronunciamiento arbitral de futuros cuestionamientos.

Por último, en los casos identificados, más que nunca será importante el deber de motivación de los laudos, porque será la única herramienta con la cual contarán las partes arbitrales para conocer por qué existe un apartamiento de los argumentos jurídicos esbozados por sus defensas jurídicas.

\section{REFERENCIAS}

Blackaby, N., y Chirinos, R. (2013). Consideraciones sobre la aplicación del principio de iura novit curia en el arbitraje internacional. Anuario Colombiano de Derecho Internacional, 6, 77-93.

Decreto Legislativo N. 295, Código Civil. (1984). Recuperado de https://www.oas.org/ juridico/PDFs/mesicic4_per_cod_civil.pdf

Decreto Legislativo N. ${ }^{\circ}$ 1071, Decreto legislativo que norma el arbitraje. (2008). Recuperado de https://portal.osce.gob.pe/arbitraje/sites/default/files/Documentos/Legisla cion_aplicable/DL-1071-ley-que-norma-el-arbitraje.pdf 
Díez-Picazo, L., y Gullón Ballesteros, A. (1982). Sistema de derecho civil (4. ${ }^{a}$ ed., vol. I). Madrid: Tecnos.

Espinoza Espinoza, J. A. (2011). Los principios contenidos en el Título Preliminar del Código Civil peruano de 1984. Lima: Editora Jurídica Grijley.

González de Cossío, F. (2011). El arbitraje. Ciudad de México: Librería Porrúa.

Silva Vallejo, J. A. (1985). El artículo VII del Título Preliminar del Nuevo Código Civil: llave maestra de la teoría general del derecho civil y procesal. En Libro homenaje a José León Barandiarán (pp. 453-493). Lima: Cultural Cuzco. 